\title{
Different Effects of Phenelzine Treatment on EEG Topography in Waking and Sleep in Depressed Patients
}

\author{
Hans-Peter Landolt, Ph.D., and J. Christian Gillin, M.D.
}

A novel approach to investigate the relationship between depression and changes in sleep-wake regulatory mechanisms used the monoamine oxidase inhibitor (MAOI) phenelzine that is known to suppress rapid-eye-movement (REM) sleep. Sleep architecture and EEG topography during wakefulness and sleep were studied in eight depressed patients before and after five weeks of treatment with phenelzine (30-90 $\mathrm{mg} /$ day), which induced a significant alleviation of depressive symptoms. Theta power (4.75-7.5 Hz) during a 5-min wake EEG prior to sleep increased two-fold during administration of phenelzine. REM sleep was almost completely eliminated. This latter effect was compensated by increased duration of stage 2, whereas total sleep time was not shortened. In non-REM sleep (stages 2, 3, and 4), treatment slightly reduced EEG power between 2.0-6.25 Hz and 8.5-13.75 Hz; power in the $16.75-25.0 \mathrm{~Hz}$ band increased. Activity in the delta band $(2.0-3.25 \mathrm{~Hz})$ tended to be reduced in the fronto-central derivation, but not in centro-parietal and parieto-occipital derivations. However, the Treatment X Derivation interaction was not significant. These data indicate that in contrast to wakefulness the effects of phenelzine treatment on the EEG in non-REM sleep were small. Rank correlation analyses revealed no association between the antidepressant treatment response and the changes in sleep and EEG power spectra during administration of phenelzine.

[Neuropsychopharmacology 27:462-469, 2002]

(C) 2002 American College of Neuropsychopharmacology. Published by Elsevier Science Inc.
KEY WORDS: REM sleep; Monoamine oxidase inhibitors (MAOI); Slow-wave activity; Theta activity; Regional differences; EEG topography

Mood and the regulation of sleep are closely related. This notion is supported by the presence of frequent sleep abnormalities in depressed patients, which may affect both rapid-eye-movement (REM) sleep and non-

From the University of California at San Diego, Department of Psychiatry, VA San Diego Healthcare System, San Diego, CA, USA.

Address correspondence to: Hans-Peter Landolt, Ph.D., Institute of Pharmacology and Toxicology, University of Zürich, Winterthurerstrasse 190, 8057, Zürich, Switzerland. Tel.: +41-1-635-5953; Fax: +41-1-635-5707; E-mail: landolt@pharma.unizh.ch

Received July 24, 2001; revised January 25, 2002; accepted February 28,2002

Online publication: 3/5/02 at www.acnp.org/citations/ Npp030502261. rapid-eye-movement (non-REM) sleep (Benca et al. 1992). A tight association between sleep and mood is further suggested by the beneficial action of total and partial sleep deprivation, as well as phase advance therapies of sleep in many patients with depression (Gillin and Borbély 1985; Wirz-Justice and Van den Hoofdakker 1999). Different theories have been proposed to account for the antidepressant effects of sleep manipulations. They include prolonged major suppression of REM sleep (Vogel 1975; Vogel et al. 1990), elevation of sleep propensity (Borbély and Wirz-Justice 1982), and reduction of non-REM sleep intensity (Beersma and Van den Hoofdakker 1992).

The timing of sleep and wakefulness and the structure of sleep are regulated by the interaction of a homeostatic, sleep-wake-dependent process $S$ and the circadian pacemaker located in the hypothalamus 
(Borbély 1982; Dijk and Czeisler 1995). Similar mechanisms may underlie the regulation of mood (Boivin et al. 1997; Wirz-Justice and Van den Hoofdakker 1999). According to the two-process model (Borbély 1982), sleep propensity (i.e. process S) accumulates during wakefulness and dissipates during sleep. The time course of this process has been estimated from low-frequency activity (power below $\sim 8 \mathrm{~Hz}$ ) in central electroencephalogram (EEG) recordings during sleep (Borbély et al. 1981; Daan et al. 1984; Dijk et al. 1987; Achermann et al. 1993). Recent studies have indicated that an EEG correlate of sleep propensity can also be measured during wakefulness. Power in the theta band $(\sim 5-8 \mathrm{~Hz})$ of the wake EEG increases during sleep deprivation (Cajochen et al. 1995; Aeschbach et al. 1997; Finelli et al. 2000). The time constant of this increase is similar to that obtained for the wake-dependent rise of delta power as measured in non-REM sleep. Furthermore, topographical analyses of the EEG during prolonged wakefulness have shown that the increase of theta activity in waking and delta activity $(\sim 1-4 \mathrm{~Hz})$ in nonREM sleep are largest in frontal EEG derivations and positively correlated (Werth et al. 1998; Cajochen et al. 1999a, 1999b; Finelli et al. 2000). These findings suggest that sleep regulation may exhibit local features. In other words, frontal parts of the cortex may be particularly susceptible to sleep loss and reflect the homeostatic process of sleep regulation more sensitively than other cortical regions.

The monoamine oxidase inhibitor (MAOI) phenelzine is an effective "first generation" antidepressant capable of virtually abolishing REM sleep (Akindele et al. 1970; Wyatt et al. 1969, 1971; Dunleavy and Oswald 1973; Landolt et al. 2001). Its antidepressant action has been proposed to be linked to the potent and long-lasting suppression of REM sleep (Vogel et al. 1990). Possible drug-induced changes in non-REM sleep, however, have not been taken into account. This is important, because alterations of REM sleep may also affect nonREM sleep. Studies in healthy subjects revealed that increased pressure for REM sleep, due to selective or preferential REM sleep deprivation by awakenings, inhibits delta activity in non-REM sleep (Beersma et al. 1990; Brunner et al. 1990). Similar changes may be expected to be associated with pharmacological REM sleep suppression.

We have recently reported that delta power in nonREM sleep was not affected in a central EEG derivation in depressed patients when REM sleep was virtually abolished during treatment with phenelzine (Landolt et al. 2001). In view of possible regional differences in sleep regulation, we have now investigated the effect of phenelzine on EEG topography in wakefulness and sleep. We predicted that a possible reduction of delta power in non-REM sleep might become apparent in frontal EEG derivations.

\section{METHODS}

\section{Patients and Study Protocol}

Eight patients ( 4 women, 4 men; mean age: $42.2 \pm 10.0$ (SD) years) who met diagnostic criteria for major depressive disorder, according to DSM-IV, participated in a treatment study with phenelzine. Seven of the patients were included in our previous publication (Landolt et al. 2001). Three patients in that previous study were excluded by the absence of artifact-free full topographical data. With the exception of three individuals who were treated for stable hypertension, no patient suffered from a medical disorder. Polysomnographic screening in the sleep laboratory served to exclude sleep apnea and/or nocturnal myoclonus. None of the patients was treated with any psychoactive or sleep medication for at least two weeks prior to the study, nor did they receive additional pharmacotherapy during the study. On sleep recording days, moderate caffeine consumption was limited to the morning hours; no alcohol was permitted for the duration of the study. Patients were instructed to keep a regular sleepwake cycle with sleep scheduled at their habitual bedtimes and to avoid naps. Written informed consent was obtained prior to the screening night, and the patients were paid for the sleep studies in the laboratory.

The study protocol was approved by the local Institutional Review Boards (IRB) of UCSD and the Veterans Administration Medical Research Foundation (VMRF). In each patient, EEG topography was recorded during a 5-min wake period immediately prior to lights-out and during the entire sleep episode during a drug-free baseline night prior to initiation of antidepressant therapy, and in weeks 3-4 and 5-6 (in week 9 in one patient) of phenelzine treatment. Each recording night was preceded by at least one adaptation night. Only the data from baseline (BL) and week 5-6 (P5) of pharmacotherapy are reported here. Open-labeled treatment with phenelzine was initiated within three days after the baseline recording, and an individual daily dose of $30-90 \mathrm{mg}$ was prescribed according to clinical considerations by a psychiatrist blind to the EEG findings. Symptoms of depression, medication side effects and vital signs were assessed within three days of each sleep study. Patients were asked to keep a sleep and dream log throughout the study period. The effect of phenelzine on dream-recall in treatment responders and non-responders has been reported elsewhere (Landolt et al. 2001).

\section{Polygraphic Recordings}

The EEG, submental electromyogram (EMG), electrooculogram (EOG), and electrocardiogram (ECG) were recorded by a portable polygraphic amplifier (PS1, Institute of Pharmacology and Toxicology, University of Zürich, 
Switzerland). The signals were digitized and transmitted via fiber-optic cables to a notebook computer with a digital signal processor board. The detailed procedures of data recording and signal conditioning are described elsewhere (Landolt et al. 2001). Briefly, EEG electrodes were placed bilaterally along the antero-posterior axes at the locations F3, F4, C3, C4, Cz, P3, P4, O1 and O2. Vigilance states were visually scored from the records of the C3-A2 derivation for consecutive 20-s epochs according to standard criteria (Rechtschaffen and Kales 1968). EEG power spectra of six bipolar derivations (F3-C3, F4-C4, C3-P3, C4-P4, P3-O1 and P4-O2) were computed off-line by a Fast-Fourier-Transform (FFT) routine for consecutive 4-s epochs during wakefulness prior to lights-out and non-REM sleep (stages 2, 3, and 4). A 10\% cosine window was applied, and spectra above $25 \mathrm{~Hz}$ were omitted. Power spectra of five consecutive 4-s epochs were averaged and matched with the 20-s stage scores. Before averaging, 4-s epochs contaminated with artifacts in any derivation (e.g. due to body movements, eye movements, sweating etc.) were visually identified and eliminated. Power spectra of homologous derivations were averaged, and the average values were used in all analyses. NonREM/REM sleep cycles in BL were defined according to the modified criteria (Werth et al. 1997) of Feinberg and Floyd (1979).

\section{Data Analyses and Statistics}

For statistical analyses the SAS General Linear Model procedure (SAS Institute Inc., Cary, NC) was used. Effects of phenelzine were assessed using 1-, 2- and 3-way analyses of variance for repeated measures (rANOVA) with the within-factors Treatment (baseline, phenelzine), Derivation (frontal-central, central-parietal, parietal-occipital) and Non-REM sleep period (1-3). If a factor had more than two levels, the presented probability values are based on Greenhouse-Geisser corrected degrees of freedom, but the original degrees of freedom are reported. If not mentioned otherwise, the significance level $(\alpha)$ was set at 0.05 . Mood, visually scored sleep variables, EEG power spectra, tonic EMG and the time course of delta power in non-REM sleep were analyzed. Values of sleep efficiency, wakefulness after sleep onset (WASO) and absolute EEG power values were log-transformed prior to statistical tests.

\section{RESULTS}

\section{Dose of Phenelzine and Treatment Response}

The average daily dose of phenelzine in week 5-6 of treatment was $58.1 \pm 6.6 \mathrm{mg}(\mathrm{SEM} ; \mathrm{n}=8)$. The treatment induced the significant improvement of depressive symptoms as assessed with the Hamilton Rating Scale of Depression (HRSD, 24 items; $\mathrm{F}_{1,7}=16.4, p<$
.004). Mean HRSD scores dropped from $23.6 \pm 1.6$ in BL to $11.8 \pm 3.7$ in $\mathrm{P} 5$.

\section{EEG Power Spectra during Wakefulness}

The waking EEG was recorded at $22.26 \mathrm{~h} \pm 11 \mathrm{~min}$ in $\mathrm{BL}$ and at $22.38 \mathrm{~h} \pm 20 \mathrm{~min}$ in $\mathrm{P} 5\left(\mathrm{~F}_{1,7}=0.3, p>.6\right.$; 1-way rANOVA with factor Treatment). During recordings, patients were instructed to relax, to keep their eyes open, and to fixate a dot on the ceiling. A 2-way rANOVA with the factors Treatment and Derivation revealed a significant effect of Treatment for all $0.25-\mathrm{Hz}$ bins between 4.75-7.5 Hz (minimum $\mathrm{F}_{1,7}=6.6, p<.04$ ). During treatment, power was increased in this frequency range independent of EEG location (Treatment: $\mathrm{F}_{1,7}=16.2, p=.005$; Derivation: $\mathrm{F}_{2,14}=2.5, p>.1$; Treatment $X$ Derivation: $F_{2,14}=0.6, p>.4 ; 2$-way rANOVA with factors Treatment and Derivation). The mean absolute power density values in BL and P5 are illustrated in Figure 1 for the centro-parietal EEG derivation.

The Spearman rank correlation between the treatment-induced increase of theta power $(4.75-7.5 \mathrm{~Hz})$ in the centro-parietal derivation (in \%) and improvement of depressive symptoms as assessed with the HRSD (in $\%)$ was not significant $\left(\mathrm{r}_{\mathrm{s}}=0.31, p>.4 ; \mathrm{n}=8\right)$.

\section{Visually Scored Sleep Variables}

All-night sleep variables in BL and P5 are summarized in Table 1 (means \pm SEM of 8 patients). The durations of non-REM sleep episodes $1-3$ in BL were $68.6 \pm 5.1$ $\mathrm{min}, 87.3 \pm 11.0 \mathrm{~min}$ and $80.5 \pm 5.0 \mathrm{~min}$. In P5, REM sleep was almost completely eliminated (range: 0-11 min). This effect was compensated by increase of stage 2 and did not shorten total sleep time. Sleep latency and sleep efficiency did not differ between BL and P5.

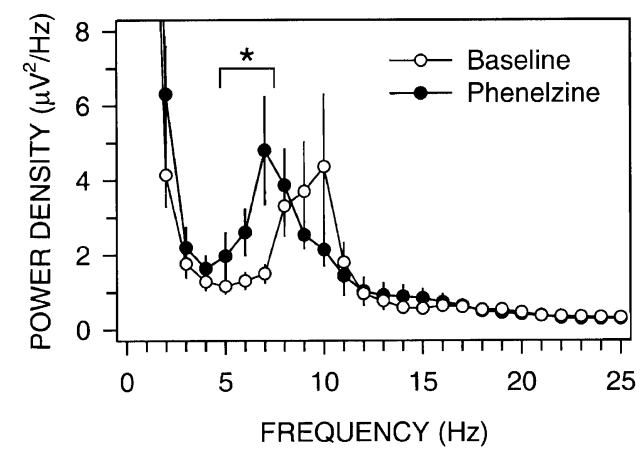

Figure 1. EEG power spectra in a 5-min wake interval prior to sleep in baseline $(\bigcirc)$ and in week 5-6 of phenelzine treatment (0). Absolute power density in each frequency bin is expressed as $\mu \mathrm{V}^{2} / \mathrm{Hz}$. Values represent means \pm 1 SEM $(\mathrm{n}=8)$ for the centro-parietal derivations averaged over the left and right hemispheres. The asterisk indicates the significant difference for the averaged frequency band $4.75-7.5 \mathrm{~Hz}\left(\mathrm{~F}_{1,7}=10.2, p<.02\right.$; 1-way rANOVA with the factor Treatment). 
Table 1. All-night Sleep Variables

\begin{tabular}{lccr}
\hline Variable & $\mathbf{B L}$ & $\mathbf{P 5}$ & $\mathbf{F}_{\mathbf{1 , 7}}(\boldsymbol{p}<\mathbf{)}$ \\
\hline Time in bed (min) & $452.5(15.8)$ & $462.1(20.3)$ & $0.2(0.71)$ \\
Sleep episode (min) & $433.0(17.4)$ & $445.3(18.5)$ & $0.3(0.63)$ \\
Total sleep time (min) & $384.7(18.5)$ & $373.2(22.5)$ & $1.0(0.36)$ \\
Sleep efficiency (\%) & $85.3(3.6)$ & $80.6(2.6)$ & $1.0(0.37)$ \\
Sleep latency (min) & $14.7(2.8)$ & $15.9(3.1)$ & $0.1(0.76)$ \\
REM latency (min) & $68.6(5.1)$ & $303.3(41.4)$ & $33.2(0.02)$ \\
WASO (min) & $47.6(17.3)$ & $68.0(13.8)$ & $7.1(0.02)$ \\
Movement time (min) & $5.5(0.8)$ & $5.1(1.3)$ & $0.2(0.68)$ \\
Stage 1 (min) & $44.3(3.0)$ & $33.6(8.9)$ & $2.2(0.19)$ \\
Stage 2 (min) & $225.0(9.9)$ & $275.0(19.8)$ & $12.3(0.01)$ \\
Stage 3 (min) & $21.9(5.3)$ & $35.0(9.5)$ & $2.6(0.16)$ \\
Stage 4 (min) & $27.8(9.0)$ & $26.0(8.7)$ & $0.0(0.86)$ \\
Slow wave sleep (min) & $49.8(13.1)$ & $61.5(17.8)$ & $0.9(0.39)$ \\
REM sleep (min) & $65.7(7.4)$ & $3.0(1.4)$ & $96.8(0.01)$ \\
\hline
\end{tabular}

Values represent means (SEM) of 8 subjects. BL: pre-treatment baseline. P5: week 5-6 of phenelzine treatment. Time in bed: time between lightsout and lights-on. Sleep episode: time between sleep onset and final awakening. Sleep efficiency: total sleep time per time in bed. Sleep latency: time from lights-off to the first occurrence of Stage 2. REM latency: time from sleep onset to the first occurrence of REM sleep. REM sleep: rapid-eyemovement sleep. WASO: wakefulness after sleep onset (stage 2). Stage 1, 2, 3 and 4: non-REM sleep stages. Slow wave sleep: stages $3+4$.

$\mathrm{F}$ and $p$ values: One-way rANOVA with the within-factor Treatment (BL, P5).

Spearman rank correlation analysis revealed no correlation between the drug-induced reduction of REM sleep (in minutes) and the percentage change in the HRSD score $\left(\mathrm{r}_{\mathrm{s}}=-0.01, p>.9 ; \mathrm{n}=8\right)$.

\section{EEG Power Spectra in non-REM Sleep}

Effects of phenelzine on all-night EEG power spectra in non-REM sleep are illustrated in Table 2 and Figure 2. A 2-way rANOVA with the factors Treatment and Derivation revealed a significant effect of Treatment in all 0.25$\mathrm{Hz}$ bins in the ranges $2.0-6.25 \mathrm{~Hz}, 8.5-13.75 \mathrm{~Hz}$ and $16.75-25.0 \mathrm{~Hz}$ (minimum $\mathrm{F}_{1,7}=5.4, p \leqslant .05$ ). In P5 power was lower than in $\mathrm{BL}$ in the fronto-central derivation in the ranges $2.75-5.25 \mathrm{~Hz}$ and $9.75-11.25 \mathrm{~Hz}$, and in the parieto-occipital derivation in the ranges $8.5-12.0 \mathrm{~Hz}$ and 13.0-13.75 Hz (Figure 2). No changes were found in the centro-parietal derivation. Within the frequency bands showing a significant Treatment effect, rANOVA identified four distinct bands with either a significant effect of Derivation and/or a significant Treatment $X$ Derivation interaction. They were located in the ranges $2.0-3.25 \mathrm{~Hz}$, 8.5-10.25 Hz, 11.5-13.0 Hz and 19.0-22.25 Hz (Table 2).

As reported in our previous paper, phenelzine treatment was associated with increased tonic EMG activity during sleep (Landolt et al. 2001). Spearman rank correlation analysis revealed that the treatment-induced increase of EEG power density in the $19.0-22.25 \mathrm{~Hz}$ band in fronto-central and centro-parietal derivations (Table 3 ) was significantly correlated with the increase of tonic EMG activity $\left(\mathrm{r}_{\mathrm{s}}=0.74\right.$ and 0.76 , respectively, $p<.04 ; \mathrm{n}=8$ ). Further EEG analyses were therefore restricted to frequencies below $15 \mathrm{~Hz}$.

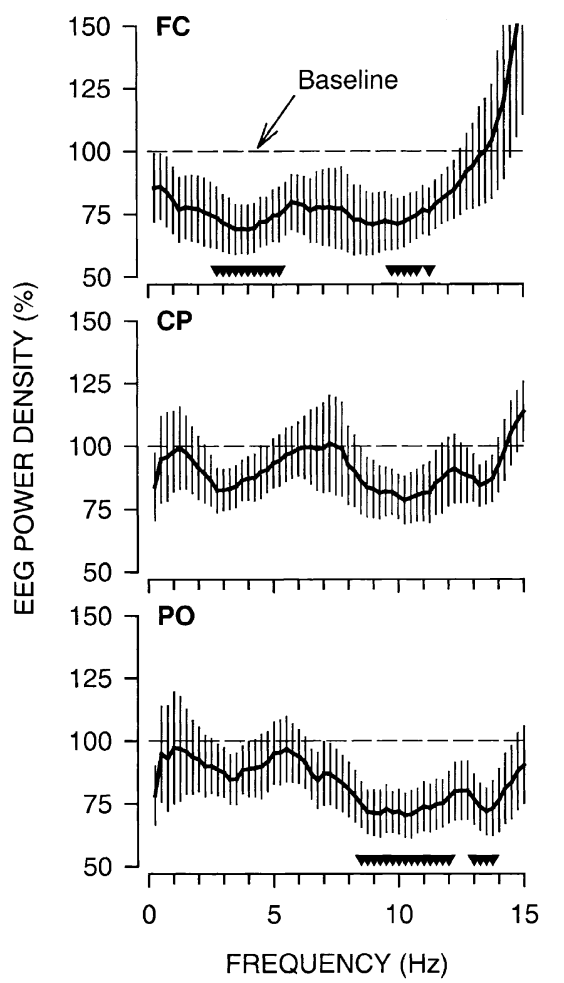

Figure 2. Relative EEG power density in non-REM sleep (stages 2, 3, and 4) during phenelzine treatment. In frontocentral (FC), centro-parietal (CP) and parieto-occipital derivations (PO), power density in each frequency bin during treatment was expressed as a percentage of the corresponding value in baseline (horizontal dashed lines at 100\%). Mean values ( \pm 1 SEM; $n=8$ ) were plotted at the upper limits of the $0.25-\mathrm{Hz}$ bins. Triangles at the bottom of the panels indicate frequency bins that differed significantly ( $\mathrm{df}=1,7$; $p<.05$; 1-way rANOVA with the factor Treatment).

A 2-way rANOVA with the factors Treatment and Derivation on log-transformed averaged power values in the $2.0-3.25 \mathrm{~Hz}, 8.5-10.25 \mathrm{~Hz}$ and $11.5-13.0 \mathrm{~Hz}$ bands revealed significant main effects (Treatment: minimum $\mathrm{F}_{1,7}=$ 9.7, $p<.02$; Derivation: minimum $\left.\mathrm{F}_{2,14}=5.6, p<.02\right)$, yet no Treatment $X$ Derivation interactions. Activity in the delta $(2.0-3.25 \mathrm{~Hz})$ and alpha bands $(8.5-10.25 \mathrm{~Hz})$ was reduced during treatment in the fronto-central derivation (Table 3). In the parieto-occipital derivation, power in P5 was below the BL values in the alpha range, as well as in the low spindle frequency range $(11.5-13.0 \mathrm{~Hz})$. No significant differences between BL and P5 were noted in the centro-parietal derivation (Table 3 ).

The Spearman rank correlation between the reduction of delta power $(2.0-3.25 \mathrm{~Hz})$ in the fronto-central derivation (in \%) and improvement of depression (in \% of HRSD score) was not significant $\left(\mathrm{r}_{\mathrm{s}}=-0.44, p>.2 ; \mathrm{n}=8\right)$.

Time Course of EEG Power in the 2.0-3.25 Hz Band in non-REM Sleep. Absolute power in the $2.0-3.25 \mathrm{~Hz}$ band was computed for the first three non-REM sleep 
Table 2. Statistical Analysis of All-night Power Spectra in Non-REM Sleep

\begin{tabular}{lcccc}
\hline rANOVA factor & df & $\begin{array}{c}\text { Frequency } \\
\text { range }\end{array}$ & F values & $\boldsymbol{p}$ values \\
\hline Treatment & 1,7 & $2.0-6.25 \mathrm{~Hz}$ & $5.4-27.1$ & $.05-.001$ \\
& & $8.5-13.75 \mathrm{~Hz}$ & $6.2-41.0$ & $.04-.0004$ \\
& & $16.75-25.0 \mathrm{~Hz}$ & $5.6-16.1$ & $.05-.005$ \\
Derivation & 2,14 & $1.0-3.25 \mathrm{~Hz}$ & $3.9-19.6$ & $.05-.0001$ \\
& & $4.0-10.25 \mathrm{~Hz}$ & $4.0-15.4$ & $.04-.0004$ \\
& & $11.5-13.0 \mathrm{~Hz}$ & $4.3-6.5$ & $.04-.01$ \\
Treatment $X$ & & & & \\
$\quad$ Derivation & 2,14 & $19.0-22.25 \mathrm{~Hz}$ & $5.5-6.1$ & $.05-.04$ \\
\hline
\end{tabular}

periods in BL and for the same time intervals in P5 (Figure 3). A 3-way rANOVA with the factors Treatment, Derivation and Non-REM sleep period revealed significant main effects (Treatment: $\mathrm{F}_{1,7}=10.4, P<.02$; Derivation: $\mathrm{F}_{2,14}=7.5, p<.02$; Non-REM sleep period: $\mathrm{F}_{2,14}=$ $45.3, p<.001)$, as well as a significant Derivation $\mathrm{X}$ NonREM sleep period interaction $\left(\mathrm{F}_{4,28}=4.5, p<.03\right)$. While the global decline of delta EEG activity across consecutive non-REM sleep episodes was not affected, power in this frequency band tended to be lower during treatment in the fronto-central derivation in the first two non-REM sleep periods (period 1: $\mathrm{F}_{1,7}=4.9, p=.06$; period 2: $\mathrm{F}_{1,7}=$ $5.3, p=.05$; 1-way rANOVA with factor Treatment).

\section{DISCUSSION}

Our study confirmed early reports (e.g. Akindele et al. 1970; Wyatt et al. 1969, 1971; Dunleavy and Oswald

Table 3. Absolute All-night Power Densities in Delta, Alpha, Sigma and Beta Frequency Bands in Non-REM Sleep

\begin{tabular}{lccrr}
\hline & BL & P5 & $\mathbf{F}_{1,7}$ & $p$ \\
\hline 2.0-3.25 Hz band & & & & \\
Fronto-central & $23.8 \pm 6.6$ & $16.8 \pm 4.7$ & 5.3 & $<.06$ \\
Centro-parietal & $27.3 \pm 7.8$ & $25.9 \pm 8.9$ & 3.0 & .13 \\
Parieto-occipital & $16.5 \pm 3.4$ & $15.7 \pm 4.1$ & 2.0 & .20 \\
8.5-10.25 Hz band & & & & \\
Fronto-central & $2.3 \pm 0.4$ & $1.6 \pm 0.4$ & 5.6 & .05 \\
Centro-parietal & $3.5 \pm 1.1$ & $2.7 \pm 0.9$ & 3.1 & .12 \\
Parieto-occipital & $3.5 \pm 1.0$ & $2.4 \pm 0.6$ & 10.1 & .02 \\
11.5-13.0 Hz band & & & & \\
Fronto-central & $1.7 \pm 0.4$ & $1.3 \pm 0.3$ & 2.3 & .17 \\
Centro-parietal & $2.1 \pm 0.8$ & $1.6 \pm 0.5$ & 2.1 & .19 \\
Parieto-occipital & $1.4 \pm 0.4$ & $1.0 \pm 0.3$ & 6.8 & .03 \\
19.0-22.25 Hz band & & & & \\
Fronto-central & $0.3 \pm 0.1$ & $2.1 \pm 1.1$ & 8.2 & .02 \\
Centro-parietal & $0.4 \pm 0.1$ & $0.7 \pm 0.1$ & 9.0 & .02 \\
Parieto-occipital & $0.4 \pm 0.1$ & $0.4 \pm 0.1$ & 0.6 & .45 \\
\hline
\end{tabular}

Values represent means \pm SEM of eight patients in $\mu \mathrm{V}^{2} / \mathrm{Hz}$ averaged over the left and right hemispheres. BL: pre-treatment baseline. P5: week 5-6 of phenelzine treatment.

$\mathrm{F}$ and $p$ values: One-way rANOVA with the within-factor 'treatment' (baseline, phenelzine)
1973) that the MAOI phenelzine is capable of inducing a virtually complete elimination of REM sleep. This effect was compensated by increased duration of stage 2 of non-REM sleep, and did not shorten total sleep time or the duration of slow wave sleep. New findings were the treatment-induced global increase of theta power during wakefulness, and the slight local changes of delta/theta, alpha, and low-sigma activity in non-REM sleep. The latter effects tended to be located in frontocentral and parieto-occipital EEG derivations and were not apparent in centro-parietal and referential central EEG recordings (Landolt et al. 2001). These results highlight the usefulness of topographical sleep EEG analyses in pharmacological studies.

Daytime sleepiness, sedation or drowsiness are frequent side effects of phenelzine (Teicher et al. 1989; Baldessarini 1995). These symptoms may or may not be related to drug-induced sleep disturbances at night. In agreement with earlier reports (Akindele et al. 1970; Wyatt et al. 1971), our study revealed no change of mean total sleep time and slow wave sleep in P5 when compared with BL. Nevertheless, six of eight patients complained of at least mild fatigue or drowsiness in week 5-6 of treatment (symptoms were severe in two patients). These side effects may be reflected in the 2-fold increase of EEG activity in the $4.75-7.5 \mathrm{~Hz}$ range during a 5-min wake period prior to sleep (Figure 1). A significant association between enhanced power in the theta band and subjective sleepiness or drowsiness is present in healthy subjects (Makeig and Jung 1996; Cajochen et al. 1999b; Finelli et al. 2000). Furthermore, the changes in the wake EEG during phenelzine treatment were reminiscent of those associated with increased sleepiness after melatonin administration (Cajochen et al. 1996) and sleep deprivation (Cajochen et al. 1995), or the differences in the waking EEG between habitual short and long sleepers (Aeschbach et al. 2001). It is interesting to note that other MAOI have been shown to increase plasma melatonin levels during day and night in psychiatric patients (Murphy et al. 1986; Van Vliet et al. 1992).

Theta activity during wakefulness and delta activity in non-REM sleep may represent closely related markers of the homeostatic process underlying sleep regulation (Finelli et al. 2000). Accordingly, it might have been expected that the treatment-induced enhancement of theta activity in the wake EEG be accompanied by increased delta power in non-REM sleep. However, slightly reduced activity was found in non-REM sleep, not only in delta/theta but also in alpha and low-sigma frequencies. These spectral changes in non-REM sleep are qualitatively similar to those observed previously after administration of the tricyclic antidepressant clomipramine to animals (Dijk et al. 1989), and the selective serotonin re-uptake inhibitor citalopram to depressed patients (Van Bemmel et al. 1993). Because significant changes in the latter study were restricted to 
Fronto-central

Centro-parietal
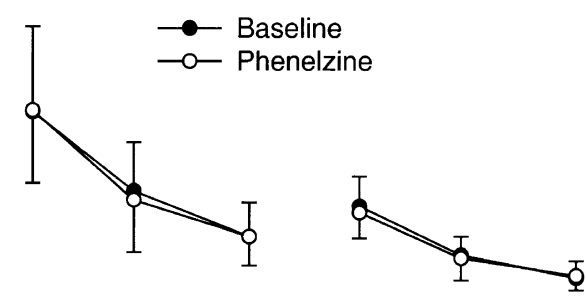

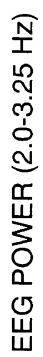

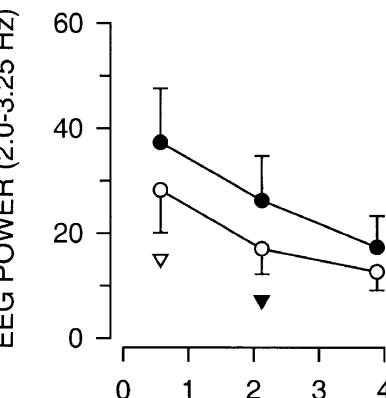

Parieto-occipital

Figure 3. Time course of delta power $\left(\mu \mathrm{V}^{2}\right)$ across the first three non-REM sleep periods in baseline and the same time intervals during phenelzine treatment. Absolute power values were plotted at the midpoint of the non-REM sleep episodes for the fronto-central, centro-parietal and parieto-occipital derivations (means, \pm 1 SEM; $\mathrm{n}=8$ ). Triangles indicate non-REM sleep periods in which power was reduced during treatment $\left(\nabla: \mathrm{F}_{1,7}=4.9, p=.06 ; \nabla\right.$ : $\mathrm{F}_{1,7}=5.3, p=.05$; 1-way rANOVA with factor Treatment).

HOURS AFTER SLEEP ONSET

the $8-9 \mathrm{~Hz}$ band and did not include lower frequencies, it was concluded that citalopram affects the sleep EEG nonspecifically and does not interfere with sleep regulatory mechanisms. Thus, caution is essential when comparing physiological mechanisms of sleep regulation and pharmacological interventions.

Although phenelzine, clomipramine and citalopram belong to different classes of antidepressants, all markedly reduced REM sleep. In accordance with the hypothesis of Beersma and Van den Hoofdakker (1992), the changes in non-REM sleep that were observed in the present study may reflect a reduction of non-REM sleep intensity due to increased REM sleep pressure. The following observations are consistent with this suggestion. First, the treatment-induced changes were state-specific and differed between wakefulness and sleep. Second, the reductions of power in non-REM sleep were located in those frequency bands, which declined gradually during pre-treatment baseline sleep (Landolt et al. 2001, Figure 1). Decreasing power in delta/theta and alpha frequencies in the course of sleep has been referred to as the 'spectral fingerprint' of sleep homeostasis (Landolt et al. 1995). Third, the treatment-induced reduction of delta activity $(2.0-3.25 \mathrm{~Hz})$ occurred in the first two non-REM sleep periods, and was restricted to fronto-central EEG derivations (Figure 3 and Table 3). These findings are consistent with the notion that frontal areas of the cortex are particularly responsive to homeostatic changes of sleep propensity (Werth et al. 1996, 1997, 1998; Cajochen et al. 1999a). And fourth, the decrease of power in the frontocentral derivation was not limited to the delta range, but included also the $8.5-10.25 \mathrm{~Hz}$ band (Figure 2 and Table 3). A close functional relationship between delta and alpha frequencies in non-REM sleep has been suggested previously (see Achermann and Borbély 1998 for discussion).

Nevertheless, the drug-induced changes in the EEG in non-REM sleep were subtle and need to be interpreted with caution. Thus, a pharmacological intervention may not necessarily reflect sleep homeostatic mechanisms. Moreover, no consistent treatment effects were evident in all bipolar derivations along the antero-posterior axis.
Also the changes in the spatial distribution of EEG power in non-REM sleep were minor and no significant Treatment $X$ Derivation interaction was found in delta, theta and alpha frequency bands. Even though phenelzine treatment virtually abolished REM sleep, enhanced theta activity during wakefulness, and tended to reduce delta power in non-REM sleep in fronto-central EEG derivations, none of these effects correlated with antidepressant response of the patients. The complexity of the treatment effects on the EEG might be related to the non-selective action of phenelzine, enhancing serotonergic, noradrenergic and dopaminergic neurotransmission (Baldessarini 1995). Monoaminergic cells of brainstem and basal forebrain have widespread projections to thalamus and cortex (Saper 1987) and may play distinct modulatory roles in the regulation of sleep and arousal (McCormick and Bal 1997).

\section{ACKNOWLEDGMENTS}

We wish to thank the faculty and staff of the UCSD Mental Health Clinical Research Center (MHCRC) for patient recruitment and clinical care, and Dr. Alexander A. Borbély, Institute of Pharmacology and Toxicology, University of Zürich, for lending us two PS-1 recording systems. We also thank Drs. A. A. Borbély and A. Wirz-Justice for comments on the manuscript. This research was supported by the Swiss National Science Foundation (823A-0566161), the National Institute of Mental Health (MH38738), the UCSD MHCRC (MH30914), the General Clinical Research Center (M01-RR00827), the Department of Veterans Affairs and the UCSD Fellowship in Psychopharmacology and Psychobiology.

\section{REFERENCES}

Achermann P, Borbély AA (1998): Coherence analysis of the human sleep electroencephalogram. Neuroscience 85: 1195-1208

Achermann P, Dijk DJ, Brunner DP, Borbély AA (1993): A model of human sleep homeostasis based on EEG slowwave activity: quantitative comparison of data and simulations. Brain Res Bull 31:97-113 
Aeschbach D, Matthews JR, Postolache TT, Jackson MA, Giesen HA, Wehr TA (1997): Dynamics of the human EEG during prolonged wakefulness: evidence for frequency-specific circadian and homeostatic influences. Neurosci Lett 239:121-124

Aeschbach D, Postolache TT, Sher L, Matthews JR, Jackson MA, Wehr TA (2001): Evidence from the waking electroencephalogram that short sleepers live under higher homeostatic sleep pressure than long sleepers. Neuroscience 102:493-502

Akindele MO, Evans JI, Oswald I (1970): Mono-amine oxidase inhibitors, sleep and mood. Electroenceph clin Neurophysiol 29:47-56

Baldessarini RJ (1995): Drugs and the treatment of psychiatric disorders. In Hardman JG, Limbird LE, Molinoff PB, Ruddon RW, Goodman Gilman A (eds), Goodman and Gilman's The Pharmacological Basis of Therapeutics. $9^{\text {th }}$ ed. New York, NY, McGraw Hill, pp 431-459

Beersma DGM, Dijk DJ, Blok CGH, Everhardus I (1990): REM sleep deprivation during 5 hours leads to immediate REM sleep rebound and to suppression of non-REM sleep intensity. Electroenceph clin Neurophysiol 76:114-122

Beersma DGM, Van den Hoofdakker RH (1992): Can nonREM sleep be depressogenic? J Affect Disord 24:101-108

Benca RM, Obermeyer WH, Thisted RA, Gillin JC (1992): Sleep and psychiatric disorders. A meta-analysis. Arch Gen Psychiatry 49:651-668

Boivin DB, Czeisler CA, Dijk DJ, Duffy JF, Folkard S, Minors DS, Totterdell P, Waterhouse JM (1997): Complex interaction of the sleep-wake cycle and circadian phase modulates mood in healthy subjects. Arch Gen Psychiatry 54:145-152

Borbély AA (1982): A two process model of sleep regulation. Human Neurobiol 1:195-204

Borbély AA, Baumann F, Brandeis D, Strauch I, Lehmann D (1981): Sleep deprivation: Effect on sleep stages and EEG power density in man. Electroenceph clin Neurophysiol 51:483-493

Borbély AA, Wirz-Justice A (1982): Sleep, sleep deprivation and depression. Human Neurobiol 1:205-210

Brunner DP, Dijk DJ, Tobler I, Borbély AA (1990): Effect of partial sleep deprivation on sleep stages and EEG power spectra: evidence for non-REM and REM sleep homeostasis. Electroenceph clin Neurophysiol 75:492499

Cajochen C, Brunner DP, Kräuchi K, Graw P, Wirz-Justice A (1995): Power density in theta/alpha frequencies of the waking EEG progressively increases during sustained wakefulness. Sleep 18:890-894

Cajochen C, Foy R, Dijk DJ (1999a): Frontal predominance of the relative increase in sleep delta and theta EEG activity after sleep loss in humans. Sleep Res Online 2:65-69

Cajochen C, Khalsa SBS, Wyatt JK, Czeisler CA, Dijk DJ (1999b): EEG and ocular correlates of circadian melatonin phase and human performance decrements during sleep loss. Am J Physiol 277:R640-R649

Cajochen C, Kräuchi K, von Arx MA, Möri D, Graw P, WirzJustice A (1996): Daytime melatonin administration enhances sleepiness and theta/alpha activity in the waking EEG. Neurosci Lett 207:209-213
Daan S, Beersma DGM, Borbély AA (1984): Timing of human sleep: recovery process gated by a circadian pacemaker. Am J Physiol 246:R161-R183

Dijk DJ, Beersma DGM, Daan S (1987): EEG power density during nap sleep: reflection of an hourglass measuring the duration of prior wakefulness. J Biol Rhythms 2: 207-219

Dijk DJ, Czeisler CA (1995): Contribution of the circadian pacemaker and the sleep homeostat to sleep propensity, sleep structure, electroencephalographic slow waves, and sleep spindle activity in humans. J Neurosci 15:3526-3538

Dijk DJ, Strijkstra A, Daan S, Beersma DGM, Van den Hoofdakker RH (1989): Effect of clomipramine on sleep and EEG power spectra in the diurnal rodent Eutamias sibiricus. Psychopharmacology (Berl) 103:375-379

Dunleavy DLF, Oswald I (1973): Phenelzine, mood response, and sleep. Arch Gen Psychiatry 28:353-356

Feinberg I, Floyd T (1979): Systematic trends across the night in human sleep cycles. Psychophysiology 16:283-291

Finelli LA, Baumann H, Borbély AA, Achermann P (2000): Dual electroencephalogram markers of human sleep homeostasis: correlation between theta activity in waking and slow-wave activity in sleep. Neuroscience 101:523-529

Gillin JC, Borbély AA (1985): Sleep: a neurobiological window on affective disorders. Trends Neurosci 8:537-542

Landolt HP, Dijk DJ, Gaus SE, Borbély AA (1995): Caffeine reduces low-frequency delta activity in the human sleep EEG. Neuropsychopharmacology 12:229-238

Landolt HP, Raimo EB, Schnierow BJ, Kelsoe JR, Rapaport MH, Gillin JC (2001): Sleep and sleep electroencephalogram (EEG) in depressed patients treated with phenelzine. Arch Gen Psychiatry 58:268-276

Makeig S, Jung TP (1996): Tonic, phasic, and transient EEG correlates of auditory awareness in drowsiness. Cogn Brain Res 4:15-25

McCormick DA, Bal T (1997): Sleep and arousal: Thalamocortical mechanisms. Annu Rev Neurosci 20:185-215

Murphy DL, Tamarkin L, Sunderland T, Garrick NA, Cohen RM (1986): Human plasma melatonin is elevated during treatment with the monoamine oxidase inhibitors clorgyline and tranylcypromine but not deprenyl. Psychiatry Res 17:119-127

Rechtschaffen A, Kales A (eds) (1968): A manual of standardized terminology, techniques and scoring system for sleep stages of human sleep. Washington, D.C.: Public Health Service, U.S. Government Printing Office

Saper CB (1987): Diffuse cortical projection systems: anatomical organization and role in cortical function. In Mountcastle VB, Plum F, Geiger SR (eds), Handbook of Physiology. Section 1: The Nervous System. Volume V: Higher Functions of the Brain, Part 1. Bethesda, MA, American Physiological Society, pp 169-210

Teicher RA, Froese C, Keller FD (1989): Common side effects associated with monoamine oxidase inhibitors. Prog Neuro-Psychopharmacol Biol Psychiat 13:497-504

Van Bemmel AL, Beersma DGM, Van den Hoofdakker RH (1993): Changes in EEG power density on NREM sleep in depressed patients during treatment with citalopram. J Sleep Res 2:156-162 
Van Vliet IM, den Boer JA, Westenberg HG (1992): Psychopharmacological treatment of social phobia: clinical and biochemical effects of brofaromine, a selective MAO-A inhibitor. Eur Neuropsychopharmacol 2:21-29

Vogel GW (1975): A review of REM sleep deprivation. Arch Gen Psychiatry 32:749-761

Vogel GW, Buffenstein A, Minter K, Hennessey A (1990): Drug effects on REM sleep and on endogenous depression. Neurosci Biobehav Rev 14:49-63

Werth E, Achermann P, Borbély AA (1996): Brain topography of the human sleep EEG: antero-posterior shifts of spectral power. Neuroreport 8:123-127

Werth E, Achermann P, Borbély AA (1997): Fronto-occipital EEG power gradients in human sleep. J Sleep Res 6:102-112
Werth E, Achermann P, Borbély AA (1998): Regional differences in the sleep EEG: Functional implications. Sleep 21, Supplement, 207

Wirz-Justice A, Van den Hoofdakker RH (1999): Sleep deprivation in depression: what do we know, where do we go? Biol Psychiatry 46:445-453

Wyatt RJ, Fram DH, Kupfer DJ, Snyder F (1971): Total prolonged drug-induced REM sleep suppression in anxious-depressed patients. Arch Gen Psychiatry 24:145155

Wyatt RJ, Kupfer DJ, Scott J, Robinson DS, Snyder F (1969): Longitudinal studies of the effect of monoamine oxidase inhibitors on sleep in man. Psychopharmacologia (Berl.) 15:236-244 